\title{
EN TORNO A UNA DE LAS "IDEAS RECIBIDAS" DE LA NARRATIVA DE GUSTAVE FLAUBERT: LA IMPERSONALIDAD
}

\author{
Dra $M^{\mathbf{a}}$ Isabel Herrero García \\ (Universidad del País Vasco)
}

\begin{abstract}
"L'auteur, dans son oeuvre, doit être comme Dieu dans l'univers, présent partout et visible nulle part."

"L'illusion (s'il y en a une) vient au contraire de l'impersonnalité de l'oeuvre. C'est un des mes principes qu'il ne faut pas s'écrire."

“J'éprouve une répulsion invincible à mettre sur le papier quelque chose de mon coeur. Je trouve même qu'un romancier n'a pas le droit d'exprimer son opinion."

(Gustave Flaubert, Correspondencia).
\end{abstract}

El concepto de impersonalidad, en contra de una creencia harto extendida, no es el pilar en el que se basa la narrativa de Gustave Flaubert: no es mas que un aspecto de su concepción de la obra artística. En efecto, Flaubert consideraba que para alcanzar la "belleza artística, el artista, valga la redundancia, debía, entre otras cosas, adoptar una actitud semejante a la del científico": no debía sentir "ni amor ni odio, ni pena ni cólera" (a George Sand, 1868); debía hacer desaparecer su "yo" para que éste no le influyera ni le condicionara su creación, el verdadero artista no cuenta su vida, no habla de sí mismo; "Notre coeur ne doit être bon qu'à sentir celui des autres" (a Louise Colet, 1853). Y, en esta perspectiva, es donde ha de ser situada la tan cacareada impersonalidad.

Tanto el concepto de obra literaria como el de Literatura tiene sus raices y su explicación en una situación socio-histórica dada: en un momento determinado, hacia mediados del siglo XIX, la Literatura, su esencia, es

1. Flaubert, en este punto, se sitúa dentro de la corriente crítica de su época, la de un Renan, o de un Taine, para los que la literatura es un campo experimental tan válido como cualquier otro en el que se manifiesta una filosofía del comportamiento: se preconica un espíritu riguroso, racionalista, científico y positivista. 
cuestionada, por lo que el principal problema que se le plantea es el problema de la forma, de su propia justificación. Problema del que no solo Flaubert fue consciente, sino también otros escritores de su generación: Gautier, Baudelaire... La respuesta de Flaubert fue la de hacer de la Literatura una "ciencia", una "escritura", ardua y de laborioso trabajo, que fue definida por Roland Barthes como "escritura aratesana":

"Se salvará a la escritura, no en función de su finalidad, sino por el trabajo que cuesta. Comienza entonces a elaborarse una imaginería del escritor artesano que se encierra en un lugar legendario... y desbasta, pule, talla y engarza su forma..."2.

Todo ello implica varios presupuestos: -la Literatura, en particular, y el Arte, en general, han de buscar su propio método: "C'est peut-être comme pour les mathétatiques, rien qu'une méthode à trouver" (a Louise Colet, 1853), "il me faudrait des choses caractéristiques comme...méthode" (a Guy de Maupassant, 1880). Método que no ha de ser único ni general, sino adecuado a cada obra, "chaque oeuvre a sa poétique en soi qu'il faut trouver". En la búsqueda de esa forma, ese método intrínseco, se situa una de las grandes intuiciones de Flaubert, convirtiéndose en una de sus grandes inquietudes como creador, sus conocidos "affres du style": los vocables están usados y existen una incapacidad del lenguaje para expresar una fusión completa entre el "alma" y la naturaleza, para "penetrar la materia" y fundirse con ella ${ }^{3}$. Para ello, el objeto a tratar ha de ser abordado en sí mismo, los hechos han de "hablar" por sí solos, el artista debe limitarse a "exponerlos", la Literatura tiene que abandonar toda tentación moralizante:

"La Littérature prenda de plus en plus les allures de la science; elle sera surtour exposante, ce qui ne veut pas dire didactique". (a Louise Colet, 1853).

Esta concepción de la literatura, brevemente expuesta, excluye todo personalismo, toda idea de causa/efecto y, por el contrario, privilegia el hecho, su esencia, el valor literario y estético de una obra vendrá dado por la "lucidez" y la adecuación formal de su tratamiento.

Ahora bien, puesto que la creación artística no puede ser la misma que la observación científica, en el proceso creativo intervendrán otros factores, sin duda menos "experimentales", tales como la asimilación de lo aprehendido (a través de la memoria, el recuerdo, la rememoración...), la imagina-

2. Le degré zéro del l'écriture, Eds du Seuil, 1953, (trad. cast. p. 67-68).

3. "Le langage en effet résiste et n'épouse jamais partaitement les formes de l'objet que l'on veut lui faire décrire puisqu'il n'est pas représentation mais création. Il a sa nature qui lui est propre, sa beauté, d'un autre ordre que celles des objets qu'il évoque. La phrase est belle en elle-même et ne rend jamais compte que d'elle-même. La tragique même de l'oeuvre et de la vie de Flaubert, tragique qu'il a vécu intensément, est dans cette distance intangible entre les mots et les choses" (P. DANGER, Sensations et objets dans les romans de Flaubert, P., A. Colin, 1973, pp. 45).

Vease La Tentation de Saint Antoine. 
ción, etc. ${ }^{4}$. Factores sobre los que no nos es posible detenernos, ya que nuestra meta en estas lineas es la de situar el concepto de "impersonalidad" en el marco de la estética flaubertiana, pero que ocupan un lugar tan privilegiado o más en el proceso de creación de Gustave Flaubert.

El concepto de impersonalidad se convirtio, junto con la objetividad, en una especie de dogma, en la esencia de su narrativa, y a partir de él se establecieron unos principios ó "reglas generales"s que toda novela debería respetar y cuya presencia y/o ausencia constituiría criterios para valorar su superioridad artística. Pero aún llegó más lejos: lo que en la Correspondencia de Flaubert no era más que una actitud estética, se identificó con la ausencia, hasta la desaparición, en el texto de su autor/narrador.

Harto conocido es el debate que se origino, a principios de siglo, y a partir de los prefacios de Henry James, en torno al concepto de "punto de vista", entendido como la relación del narrador con la historia que él mismo cuenta y en palabras de Percy Lubbock. Una serie de intentos se llevaron a cabo para establecer una oposición única que permitiera organizar los rasgos de la relación entre el narrador y el universo representado ${ }^{6}$. Para ello, se retomó la antigua oposición entre "mímesis" (lo mostrado -ausencia de narrador) y "diegesis" (lo contado- presencia del narrador), el "showing" y el "telling", empleados por la crítica anglosajona. El primer tipo de relación consiste, principalmente, en dejar que los hechos hablen por sí solos, el relato aparece "comme quelque chose qui doit être montré, qui doit être offert au lecteur et s'imposer de soi-même"7: el autor se hallaría totalmente ausente del relato y los acontecimientos se desarrollarían directamente ante el lector. Por el contrario, el segundo tipo de relación, el "telling", consitiría en la adopción de un punto de vista omnisciente: el autor asume, en el relato, la posición de un dios que conoce a fondo sus personajes, el sentido de sus acciones, sus pensamientos más íntimos y que posee la clave de su destino.

A partir de estas reflexiones, tanto novelistas como críticos consideraron que "lo mostrado" tenía un grado artístico más elevado que "lo contado", y pocas fueron las voces que se levantaron, en la época, en contra de

4. Imaginación que se va transformando en una "rêverie", un ensueño que se manifiesta en el texto a través de una mirada que se alarga, que "imagina" los objetos más allá de su percepción real. Es la mirada típica de las descripciones flaubertianas, de los mundos imaginarios de los "livres romantiques" de Mne Bovary, de los "palais à la moresque" de Frédéric Moreau.

5. "Las auténticas novelas deben ser realistas; todos los autores deberían ser objetivos; el verdadero arte ignora al público; emociones, creencias y objetividad del lector" (W. C. BOOTH, La Retórica de la ficción, Barcelona, Ed. Bosch, 1974; Ed. org. 1961.

6. P. LUBBOCK, The Craft of Fiction, London, Jonathan, cap. $4^{\circ}$ (reproducido en Flaubert (textes recueillis et présentés par R. Debray-Genette), P., Firmin-Ditor Etude, 1970, coll. "Miroir de la critique". Las citas corresponden al capítulo $5^{\circ}$.

7. Ib. pp. 74. 
la aceptación de este dogma de la "objetividad", de la "impersonalidad", de la "ausencia del autor del texto". Superioridad artística de "lo mostrado", "reglas generales" serán posteriormente refutadas, tomando como criterio la necesaria y obligatoria presencia en el texto del narrador del mismo, algunos, lease Kayser", llegarán a sentenciar que "la muerte del narrador supondrá la muerte de la novela".

Tales refutaciones se basan tanto en una nueva concepción de la novela, como en una renovación de la crítica, en la que confluyen las aportaciones de otras ciencias, como la lingüistica, y una nueva consideración sobre la labor de ésta última, que bien podríamos resumir en el planteamiento de $\mathrm{W}$. C. Booth:

"Mi tema es la técnica de la ficción no didáctica considerada como el arte de comunicarse a los lectores; los recursos retóricos disponibles al escritor... que intenta consciente $o$ inconscientemente imponer su mundo ficticio al lector"10.

Por ello, en el análisis de las técnicas narrativas, se rechazan las reglas generales y, naturalmente, entre ellas, la que se había convertido en una especie de "mito": la impersonalidad, la desaparición del autor de la novela:

"El juicio del autor está siempre presente y es siempre evidente para cualquiera que sepa cómo buscarlo. Si sus formas particulares son perjudiciales o aprovechables es siempre una cuestión compleja, que no puede determinarse con una fácil referencia a reglas abstractas" $" 11$.

Paralelamente, en torno al problema del "punto de vista" se habían producido determinadas identificaciones que, tanto la obra de Booth como posteriormente los estudios de la poética estructuralista francesa, revelarán falsas. Se identificaba el autor de un texto con el narrador del mismo, idenatificación que aún iba más allá: ese narrador correspondía al narrador omnisciente y totopoderoso cuya desaparición suponía la "muerte" de todo autor/ narrador. Asimismo, distintas categorías del relato eran confundidas: el modo, la visión, la voz narrativa, bien es cierto que dichas categorías se hallan íntimamente relacionadas.

El texto de todo relato, y por tanto de la novela, está atravesado por distintas y diferentes "voces" e instancias narrativas, entre las que naturalmente se encuentra la voz del autor/narrador; voces que impiden considerar

8. Entre ellas cabe destacar la de E. M. Forster, Aspects of the Nove considera la novela como el arte de la abstracción y de la interpretación, que da forma a la realidad, y no cabe hablar tanto de reglas o normas como de "aspectos".

9. “Qui raconte le roman?" in Poétique du récit, P., Eds du Seuil, 1977.

10. Op. Cit., pp. VII.

11. Ib. pp. 19 . 
el texto narrativo como un texto totalmente objetivo, sino más bien todo lo contrario: l'objet principal du genre romanesque qui le spécifie, qui crée son originalité stylistique, c'est l'homme qui parle et sa parole"12, y no se trata tanto de discutir sobre su ausencia y/o presencia como de analizar los grados $\mathrm{y}$ formas de esa presencia.

En esta prespectiva, W. C. Booth introduce el término de "autor implícito" como uno de los aspectos del narrador, que "incluye la aprehensión de un todo artísticamente completo, cuyo principal valor al que "este" autor implícito está comprometido, prescindiendo del partido a que pertenece su creador en la vida real, es el que queda expresado por la forma total"13. Dicho autor implícito sería por tanto, el organizador del texto, el responsable de la marcha y desarrollo de la ficción, el que impone una determinada estrategia narrativa y ritmo al relato, sería áquel que la crítica biográfica identifica con el hombre, pero que sin embargo no es posible identificar, pues como decía Barthes "qui parle (dans le récit) n'est pas qui écrit (dans la vie) et qui écrit n'est pas qui est"14.

Esta distinción entre autor y autor implícito permite explicar desde otra perspectiva, lo que muchos consideraban "quebrantamientos" a la regla de objetividad e impersonalidad de Gustave Flaubert: las "intrusiones del autor" 15 , así como el relativo "fracaso" de nuetro autor al no conseguir una obra plenamente impersonal, como señalan algunos manuales:

"A vrai dire, en dépit de tous ses efforts, Flaubert n'est pas parvenu á réaliser una oeuvre parfaitement impersonnelle. Il laisse parfois deviner son humeur, surtout quand il raille la sottise bourgeoise: plutôt qu'une vision impartiale du monde, ses romans reflètent le pessimisme fondamental de l'ermite de Croisset"16.

Tal fracaso, tales infracciones reciben una explicación coherente debido a la existencia de esa imagen implícita en todo texto que él mismo crea y que no es identificable con su autor real.

Una posible definición de la "visión" ó "punto de vista" sería la(s) relacion(es) que mantienen el narrador (distinguiéndole del autor implícito, según lo que acabamos de exponer) y el personaje, es decir entre los dos protagonistas del acto discursivo: el "yo" del discurso y el "el" de la historia, tomando la distinción lingüistica ${ }^{17}$, se trata, en suma, de la relación del dis-

12. M. BAKHTINE, Esthétique du roman, Paris, Eds Gallimard, 1978, p. 106.

13. OP. CIT., p. 69.

14. "Analyse structurale du récit" in Communications 8,1968 , p. 34.

15. Como las que señala $\mathrm{Cl}$. GOTHOT-MERSCH, "le point de vue dans Madame Bovary" in C. A. I. E. F. 23, 1971, p. 243-259.

16. LAGARDE \& MICHARD, Le XIXéme siécle, Paris, Bordas, 1964, p. 457.

17. Tz TODOROV, "problémes de l'énonciation" in Langages 17, 1970; "Les catégories du récit llitéraire" in Comunications 8, 1968.

Poétique, Paris, Eds. du Seuil, 1968.

G. GENETTE, Figures III, Paris, Eds. du Seuil, 1972. 
curso con la ficción que él mismo crea.

Ahora bien, existe otra posible perspectiva de análisis; cómo ese narrador cuenta la historia, si se limita a "contarla" o por el contrario a "mostrarla". En este caso estamos ante la categoria del relato denominada "modo"18.

Para terminar de refutar las "reglas generales" a las que venimos aludiendo, así como para esclarecer las distintas categorias narrativas, creemos necesario añadir algo sobre la voz narrativa. Decíamos anteriormente que el texto de la novela está atravesado por distintas voces que bien podíamos resumir en las siguientes: autor implícito-narrador-personaje-lector implícito; voces o instancias narrativas que constituyen la natauraleza intrínseca de la novela, cuya estructura responde a la de un acto comunicativo que existe que haya un alguién (el narrador) que cuente algo (la historia) a alguién (el lector). En el marco de esta estructura, la voz narrativa constituye el elemento base.

Las breves consideraciones que hemos ido exponiendo sobre las distintas instancias narrativas de la novela, así como el lugar que el concepto de impersonalidad ocupa en la estética flaubertiana, nos llevan a plantearnos el cómo ha de ser interpretada y cómo ha de definirse hoy día esa "actitud impersonal" preconizada por nuestro autor. ¿Acaso no es más que una aspiración difícilmente asequible e incluso utópica hacia la consecución de un relato totalmente objetivo, Flaubert precursor del "nouveau roman"?. En este presupuesto, su teoría literaria entraría en flagrante contradicción con su práctica narrativa, siempre y cuando sea aceptada la identificación impersonalidad $=$ ausencia del autor/narrador. Práctica narrativa que, asimismo, se saldaría con un rotundo fracaso, pues en la mayoria de las novelas de Gustave Flaubert existe una voz narrativa, en su doble distinción: narrador y autor implícito; voz narrativa que no solo se manifiesta a través de los indicios lingïsticos de la enunciación ${ }^{19}$, sino que también penetra en las otras voces de la novela, mediatizando todo su discurso.

Ahora bien, cabe plantearse el problema desde otra perspectiva: $¿$ acaso la impersonalidad flaubertiana no es más que la respuesta dada a una serie de problemas que el novelista se plantea ante una determinada realidad que la novela ha de significar y traducir? ¿acaso la impersonalidad no es mas que otro elemento de toda una estrategía narrativa adoptada, y que tal impersonalidad no ha de ser interpretada como la presencia y/o ausencia del autor en el texto?. En las líneas que siguen trataremos de demostrar cómo, a nuestro juicio, ese concepto de impersonalidad, como otros muchos preconizados por Flaubert, ha de ser estudiado desde esta segunda perspectiva: la res-

18. Vease bibliografía nota 17. Se trata de la "antigua" oposición entre la "diegeis" ó la "mimesis", el "telling" ó el "showing" de los anglosajones. Vease supra.

19. Este trabajo ha sido llevado a cabo por mí misma, "La voz narrativa en L'Education Sentimentale" in Théléme, 1982. 
puesta dada a determinados problemas y una de las partes integrantes de su narrativa.

Si admitimos que la temática de la novela, principalmente la denominada "novela realista" decimonónica, gira en torno a la relación exitente entre dos entidades: el individuo y el orden social, la forma de la misma dependerá tanto de la naturaleza de ambas como del tipo de relación que mantienen.

Durante un periodo determinado de la historia de la novela existía una "casi" completa identificación: el "individuo", al menor virtualmente, podía alcanzar sus "ideales", desarrollar y realizar sus aspiraciones en el marco de la vida social, pues ambos eran coincidentes. Así, para Balzac toda la vida humana estaba regida por una serie de leyes, de reglas elaboradas y dictadas por la sociedad y a las que el individuo debía adaptarse y/o hacer suyas: la ambición de un Rastignac es tan individual como social ${ }^{20}$. Para traducir esta realidad bastaba el narrador omnisciente y todopoderoso:

"Le romancier est totalement souverain, parce qu'à ses yeux il n'y a pas de réelle différence entre le sujet créateur et l'objet créé: le second détermine le premier, oriente son point de vue; l'écrivain est en quelques sorte le délégué de la Société, dont les lois, les règles, les structurations et les destructurations succesives fournissent le plan de l'oeuvre et en dictent l'esprit"21.

Sin embargo, a partir de un determinado momento, hacia mediados del siglo XIX, comienza a manifestarse la crisis de ese narrador "soberano" por la comprobación de que no solo entre ambas entidades, individuo y orden social, existe una ruptura total e insalvable, sino que también porque ambas entidades son de naturaleza distinta: se produce el conflicto entre el individuo y el orden social, entre la objetividad y la subjetividad. Conflicto del que Flaubert fue plenamente consciente y que ya Stendhal intuyó materializándolo en sus "restricciones del punto de vista"22.

Y si el hombre ya no puede tener una visión del mundo en armonía con su propia individualidad, y si ambas entidades ya no son coincidentes, "se ha perdido la totalidad" en palabaras de George Lukács, ya no es posible que la novela presente una visión total y objetiva cual era la del narrador todopoderoso; se hace necesario que esa realidad sea percibida por una subjetividad, sea descrita a partir de una sensibilidad, llamese Madame Bovary, Félicité, Frédéric Moreau...

Ahora bien, otras comprobaciones y hechos irán agudizando esa crisis de la tradicional omnisciencia: el hombre no pude abarcar la totalidad del mundo de forma objetiva, no solo por su complejidad creciente y manifiesta

20. G. LUKACS, Teoria de la novela (obras completas de Barcelona Grijalbo, 1975).

21. M. ZERAFFA, Personne et personnage, Paris, Klincksieck, 1969, p. 41.

22. Véase G. BLIN, Stendhal et les problémes du roman, Paris, P. Corti, 1953. 
sino también por el hecho de que el hombre no posee un modo de percepción y conocimiento adecuado para aprehender el "mundo" de forma global y total: la imagen que de él posee es una imagen parcial, fragmentada, que difiere de un individuo a otro y que se halla supeditada a su estado anímico, el hombre posee una visión relativista de la existencia: decía nuestro autor, "il n'y a de vrai que dans "les rapports", c'est-a-dire, la façon dont nous percevons les objets" (a Guy de Maupassant, 1878).

Esta nueva realidad asi como un nuevo concepto de la Literatura y esa crisis del narrador omnisciente llevaron a Gustave Flaubert a la adopción de unas determinadas técnicas narrativas en consonancia con dichos presupuestos. Técnicas narrativas que aceptando la terminología y los presupuestos de Gérard Genette ${ }^{23}$ estan englobadas en lo que el mismo autor denomina "el aspecto verbal" del relato, lease de la novela:

- "modo" (o visión): problemas relacionados con la regulación de la información narrativa y que dependen de dos modalidades esenciales: la "perspectiva", el personaje que orienta la perspectiva narrativa, valga la redundancia, y la "distancia", diegesis y mimesis - narración y representación;

-voz: quien asume la historia de este relato.

No es nuestro propósito el exponer de forma exhaustiva los principales rasgos de cada una de estas categorias del aspecto verbal en las novelas de Gustave Flaubert, ya que tal empresa desbordaría los límites del presente artículo y, asimismo, la meta propuesta: la de demostrar que el concepto de "impérsonalidad" flaubertiana no es más que "otro" elemento de su estética y está en estrecha vinculación a toda una estrategía narrativa.

Basta abrir al azar cualquier de las novelas de Gustave Flaubert para poder apreciar cómo el mundo, la ficción, nos es transmitida a través de un personaje, tamizada por él. A través de ese personaje, que por ello adquiere en la novela el status de personaje central, conoceremos tanto su propia personalidad, su propio mundo, como el mundo circundante. Todo "pasa" a través suyo, y no como una observación imparcial, sino "tal como se le aparece y sólo en la medida en que se le aparece"24.

De ello, se deriva una limitación, una restricción: el personaje sólo puede ver y observar aquello que entra dentro de su campo visual, a menudo ese personaje "ve" y "oye cosas" sin comprenderlas, y la información suplementaria no es suplida por el narrador, sino que es simplemente sugerida.

De esta "tamización" de los hechos y del mundo se desprende una consecuencia importante: el de sugerirnos "otra" realidad que no es la descrita,

23. Op. Cit.

24. Se trata de la denominada "visión con". J. POUILLON, Temps et roman Paris, Gallimard, 1946. 
una realidad a la que no se tiene un acceso directo e inmediato ya que se trata de una realidad inconsistente, fugitiva, constituida por impresiones de un instante, por esa "trama de la existencia cotidiana". Arte de sugerir que es algo innato al genio flaubertiano mostrando una clara preferencia hacia el reflejo del hecho o acontecimiento en la conciencia que al acontecimiento mismo.

Todo ello nos lleva a caracterizar la perspectiva narrativa de las novelas de nuestro autor como de "realismo subjetivo"ó la percepción de lo real depende de una sensibilidad, de una subjetividad, y de "realismo sugestivo": se trata de dejar entrever más que de mostrar.

De las dos formas de "distancia" narrativa existentes, la narración o diegesis y la representación o mimesis, Flaubert preferirá las relacionadas con ésta última. En efecto, todas sus novelas, salvo las denominadas por él mismo como "filosóficas", esto es La Tentation de Saint Antoine, en sus dos versiones, la de 1848-49 y la de 1874, y Bouvard et Pécuchet, están configuradas en torno a una serie de "escenas", sus conocidos "tableaux", unidos entre sí por un hilo argumental. Esta composición en escenas posee un profundo significado que ya avanzó Albaert Thibaudet ${ }^{25}$ : se trata de una composición destinada a dar sensación de vida, de un fluir que no está encerrado y que no posee ni principio ni fin.

La adopción de las formas narrativas relacionadas con la "representación" como modo esencial de sus novelas es una consecuencia directa de su concepto "científico" de la Literatura y del papel del escritor, éste ha de limitarse a mostrar los hechos, a exponerlos: "Il faut faire des tableaux, montrer la nature telle qu'elle est, mais des tableaux complets,peindre le dessous et le dessus" (a Louise Colet, 1853). Pero, asimismo, es consecuencia de su deseo y aspiración de ser "impersonal", de no escribirse a sí mismo, de no concluir, "contenons-nous du tableau, c'est aussi bon" (a Louis Bouilhet, $1850)$.

Por otra parte, esta elección encuentra también su explicación en la situación social del escritor: su total aversión a la sociedad le lleva a refugiarse en su "torre de marfil" y a convertirse en un "observador crítico de la sociedad y de su época", tal como lo definiera Lukács. Esa sociedad se halla caracterizada por la falta de relación entre la acción y aspiraciones de los hombres y los acontecimientos del mundo exterior, por la invasión y dominio del aburrimiento, de la monotonía, por la falta de "originalidad". Por lo que el artista debe limitarse a mostrar esa "monotonia", ese constante paso del tiempo, consciente de que el fenómeno así mostrado se interpretará por sí solo, sin necesidad de que el autor intervenga, lo haga explícito. Proyecto que ya entrevió George Sand en su opinión sobre L'Education Sentimentale: "Que prouve ton livre?...Il prouve que cet état social est arrivé à 
sa décompositaion et qu'il faudra le changer très radicalement. Il le prouve si bien qu'on ne te croirait pas si tu disais le contraire..."26.

Tal como acabamos de exponer la técnica narrativa adoptada por $\mathrm{G}$. Flaubert está basada, por un lado, en la "representación escénica" y, por otro, en la visión subjetiva de uno de los personajes de la novela, el protagonista. Estas bases implicarían, en lógica consecuencia, la desaparición del narrador: la novela estaría constituida por una "historia" que se narra a sí misma: "nadie habla; los acontecimientos parecen contarse por sí solos", según la definición dada por $\mathrm{E}$. Benveniste ${ }^{27}$. Definición que se ajustaría al ideal flaubertiano: escribir una novela tal como se escribe una "historia", haciendo desaparecer el "yo" y adoptando una actitud científica de objetividad e impersonalidad.

Ahora bien, sabemos que la desaparición completa del "yo" en una novela, la desaparición del narrador, es poco menos que imposible, difícil de lograr y hasta utópica: siempre existirá un pequeño matiz, una mínima inflexión de voz que señale su presencia. Por otra parte, esa desaparición del autor-narrador es poco menor que imposible puesto que él es el creador de ese universo ficticio, esencia de la novela, él es la representación del mismo principio novelesco (Grivel).

El hecho de considerar la novela, como cualquier relato, como un acto de comunicación que se establece entre ese narrador y el lector, implícitos en la misma, hace imposible la desaparición de uno de ellos.

Así pues considerando todas estas premisas no se trata tanto de discutir sobre la existencia y/o presencia del narrador en las novelas flaubertianas sino de analizar la materialización de su presencia. Presencia que plantea dos serie de problemas, que debido a razones ya expuestas nos limitaremos a señalar: 1) en torno a la posición adoptada por el narrador en relación con el relato: narrador que es un personaje más del mismo y que "narra" los acontecimientos como participante (narrador interno) ó narrador ausente del relato, externo. Salvo el comienzo de Mme Bovary, "Nous" étions á l'étude quand le Proviseur entra..." y su final "Il vient de recevoir la Légion d'honneúr", la preferencia de Flaubert se dirige hacia el narrador externo. 2) Indicios de su presencia que puede manifestarse ya sea en la organización de la novela ya sea en el propio discurso de la misma, los indicios lingüisticos. Salvo dos escenas existentes en Mme Bovary (la escena de la boda, $1^{\mathrm{a}}$ parte, cap. IV, y la visita de Emma al cura, $2^{a}$ parte, cap. VI) que parecen acercarse a ese relato impersonal que se cuenta por sí solo, el narrador flaubertiano e incluso el autor se manifiesta en los quebrantamientos al orden cronológico de los acontecimientos (ej. los "flash-back"), la variación del

26. Artículo aparecido en La Liberté, 22 de diciembre de 1869.

27. “L'appareil formel de l'énonciation” in Langages 17, mars 1970, p. 12-18. 
ritmo global, del tempo del relato (ej. aceleración del mismo, ó los famosos "blancs":

Il voyagea.

Il connut la mélancolie des paquebots" “(L'Education Sentimentale, $3^{\mathrm{a}}$ parte, cap. VI), ó la paralización por la descripción de un objeto: la virtuosidad de la descripción de la "casquette" de Charles, el pastel de bodas, etc...). En lo que concierne a los indicios lingüisticos, el narrador prefiere aquellos en los que su presencia se revela más ambigüa, más velada. Así, en sus comentarios sobre la acción, personalizan, comportamiento de sus personajes, en las exposición de las "ideas" de la sociedad de la novela, topicos, "idées recues", etc... Flaubert empleará el denominado "estilo (discurso) indirecto libre" que de forma tan admirable traduce dicha ambigüedad.

Sin duda a todo ello habría que añadir, como indicio de la presencia del autor/narrador, la existencia, en la mayoria de sus novelas, de un "tono", un vocabulario, en suma de un discurso locutivo, fuertemente evaluativo (empleo de términos peyorativos, irónicos ...) a través del cual Flaubert transmite, de forma impersonal, su visión y su actitud hacia la realidad: está no es más que un espéctaculo que ha de ser visto y observado como si se tratara de "une blague supérieure". 
